\title{
A Study on Megaloblastic Anaemia and Pancytopenia
}

\author{
P. Sashikanth Reddy', S. Srinivas ${ }^{2}$ \\ ${ }^{1}$ Associate Professor of medicine RVM medical college, Medak, Telangana, ${ }^{2}$ Professor and HOD, medicine, MNR medical college Sangareddy, Telangana.
}

\section{Abstract}

Background: Megaloblastic Anaemia and pancytopenia are common medical problems, Vitamin $\mathrm{B}_{12}$ and folic acid deficiencies are common causes for megaloblastic Anaemia. Pancytopenia is a condition where bone marrow becomes hypo plastic fails to produce mature blood cells, causes include myelodysplasia leukemia's, drugs and ionizing radiation and always associated with decreased reticulocyte count. Megaloblastic Anaemia is commonly due to dietary deficiency and pregnancy. Aim: To study about megaloblastic Anaemia\& pancytopenia. Subjects and Methods: In our study we have examined 120 Anaemia patients for 1 year.out of these 120 patients most of than are having Iron deficiency Anaemia 32 patients are having megaloblastic Anaemia and 26 patients are having pancytopenia. after complete history taking and clinical exmination we have send the blood samples for investigations. Results: Total no. of megaloblastic Anaemia were 32 patients Males 18 , Females 14 and the total no. of pancytopenia patients were 26 out of these 26, 15 were Males and 11 were Females common age group is 20 years and 40 years, The clinical features are fatigue, shortness of breath, parenthesis's, Fever, Splenomegaly pallar are present in most of the cases. Conclusion: megaloblastic Anaemia and pancytopenia are common medical problems in India, especially rural areas, they should be suspected is pregnant woman with prolonged fever, Anaemia\& bleeding tendencies and lympledinopathy.

Keywords: Megaloblastic Anaemia, pancytopenia, macrorytosis, hemoglobin, splenomegaly.

Corresponding Author: Dr. S.Srinivas Prof. and HOD medicine, MNR Medical college. Sangareddy Telangana.

Received: August 2019

Accepted: October 2019

\section{Introduction}

Anaemia are very common hematological disorders in India and worldwide. After Iron deficiency Anaemia, megaloblastic Anaemia is very common in pregnant women and in old age individuals. Pancytopenia is associated with aplastic Anaemia. The Incidence of acquired aplastic Anaemia in Europe and Isreal Is 2 case per million person annually. In Thailand and china 5-7/million. ${ }^{[1]}$ The hypo proliferative Anaemia are norm chromic normocytic or macrocytic and are characterized by low reticulocyte count hypo proliferative Anaemia are also a prominent feature of hematologic diseases that are described as bone morrow failure states, these include aplastic Anaemia, myelodysplastic syndrome (MDS)pure red cell aplasia. ${ }^{[2]}$

Megaloblastic Anaemia are a group of disorders characterized by the presence of distinctive morphologic appearance of developing red cells in the bone marrow. The marrow is usually hyper cellular and the Anaemia is based on ineffective erythropoiesis. Causes may include deficiency of folic acid or vitamin $\mathrm{B}_{12}$ or defects in DNA synthesis. ${ }^{[3]}$ Cobalamin is synthesized solely by microorganism. Only source for humans is food of animal origin eg: meat, fish, milk products, Vegetables, fruits and other non-animal origin are free from cobalamin unless they are contaminated by bacteria, Normal western diet contains 5-30mg of cobalamin daily. Adults daily losses are $1-3 \mathrm{mg} 0.1 \%$ of body stores are of the order of $2-3$ sufficient for $3-4$ years if supplies are completely cut off ${ }^{[4]}$ (PM10: 2343842).
Folic acid is the term commonly used for pleroylmonoglutamic acid. Folic acid is present in most fruits and vegetables acid. Daily requirements are 50-100 MCGs. ${ }^{[5]}$

The more frequent findings in pancytopenia are Anaemia leukepemia's and thrombocytopenia blood counts in marrow failure disease results from deficient hematopoiesis a distinguished from blood count depression due to peripheral distribution of red cells (hemolytic Anaemia)platelets (Idiopathic thrombocytopenic purpura (ITP)) or due to splenomegaly and granumalocytis (as in immune leukepemias. Marros damage and dysfunction also may be secondary to infection, inflammation or cancer) ${ }^{[6]}$

\section{Subjects and Methods}

We have examined 120 Anaemia patients for 1 year out of these 120 most of them are having Iron deficiency Anaemia. 32 patients are having megaloblastic Anaemia and 26 patients are having pancytopenia after careful history taking and clinical examination the blood samples have been send for investigation. The investigation advised are, Hemoglobin. Total count and differential count, platelet count, reticulocyte count, packed cell volume and RBC indices. Peripheral smear examination was done with wrights stain. In megaloblastic Anaemia out of 32 patients 19 are males 13 are females. In pancytopenia out of 26 patients 15 were males 11 are females. The age group is 20 years to 60 years. 
The diagnosis is based on peripheral smear examination and bone marrow aspiration. The inclusion criteria are $\mathrm{HB} \%$ is less than $10 \mathrm{gm}$. Platelets count is less than 1,00,000/cumm and WBC count is less than 4000/cumm.

Complete haemogram including platelet count and mean corpuscular volume(MVC) were also carried out in each child using coulter T860 particle counter. The platelet count obtained from counter counter was always confirmed by peripheral smear examination biochemically pure vitamin B12 deficiency and folic acid deficiency were diagnosed when serum level were below $80 \mathrm{~kg} / \mathrm{ml}$ and $3 \mathrm{mg} / \mathrm{ml}$ respectively.

\section{Results}

We have divide the age group into $10-19 y r s, 20-29 y r s$, $30-39 y r s, 40-49 y r s$ and $>50 y r s$.

Peripheral smear showed predominantly macrocytic macro ovulocytes and pear shaped poikilocytes hyper segmentation of large signed neutrophils was seen in all cases. The criteria for hyper segmentation of polymorphs was likens to be the presence of increasing no. of neutrophils with five or more nuclear lobes.

\section{Age wise Distribution in megaloblastic}

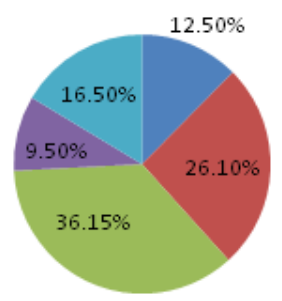

10-19yrs

-20-29yrs

- 30 - 39yrs

-40-49yrs

nav $>50 \mathrm{yrs}$

\section{Graph 1: Age wise distribution in Megaloblastic anaemia.}

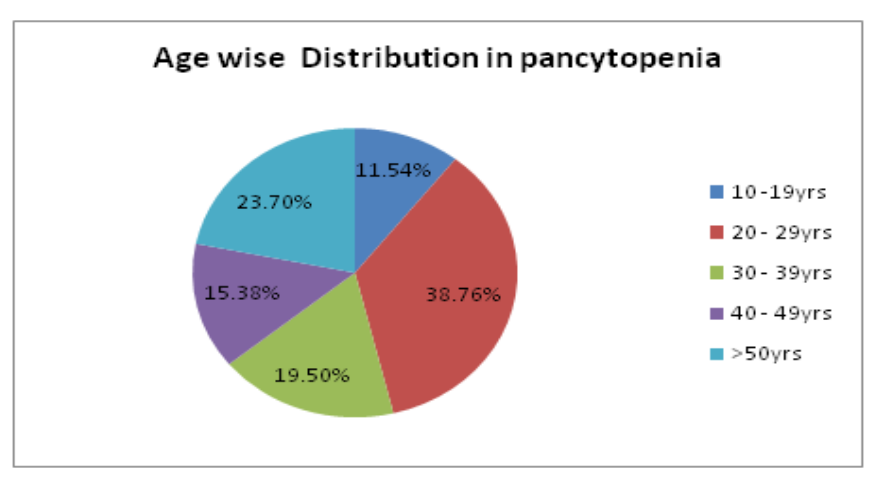

Graph 2: Age wise distribution in Pancytopenia.

Table 1: Age wise Distribution in megaloblastic

\begin{tabular}{|l|l|l|}
\hline Age & No. of Cases & Percentage \\
\hline $10-19 \mathrm{yrs}$ & 4 & $12.5 \%$ \\
\hline $20-29 \mathrm{yrs}$ & 8 & $26.10 \%$ \\
\hline $30-39 \mathrm{yrs}$ & 12 & $36.15 \%$ \\
\hline $40-479 \mathrm{yrs}$ & 3 & $9.50 \%$ \\
\hline$>50$ & 5 & $16.50 \%$ \\
\hline
\end{tabular}

Table 2: Age wise Distribution in pancytopenia

\begin{tabular}{|l|l|l|}
\hline Age & No. of cases & Percentage \\
\hline $10-19 \mathrm{yrs}$ & 3 & $11.54 \%$ \\
\hline $20-29 \mathrm{yrs}$ & 8 & $38.76 \%$ \\
\hline $30-39 \mathrm{yrs}$ & 5 & $9.50 \%$ \\
\hline $40-49 \mathrm{yrs}$ & 4 & $15.38 \%$ \\
\hline$>50 \mathrm{yrs}$ & 6 & $23.07 \%$ \\
\hline
\end{tabular}

Table 3: Clinical Factures

\begin{tabular}{|l|l|l|}
\hline Clinical facture & No. of Cases & Percentage \\
\hline Fatigue & 28 & $84.35 \%$ \\
\hline Pallar & 36 & $100 \%$ \\
\hline Fever & 6 & $16.52 \%$ \\
\hline Hepatosplenomegaly & 5 & $14.25 \%$ \\
\hline Jaundice & 4 & $12.38 \%$ \\
\hline Others & 2 & $6.25 \%$ \\
\hline
\end{tabular}

The common clinical feature includes, fatigue, pallar. Shortness of breath, fever, palpitation, parenthesis sensory symptoms hepatosplenomegaly, jaundice. The common causes are with $\mathrm{B}_{12}$ deficiency, dietary deficiencies, infections, MDS, and leukemia's.
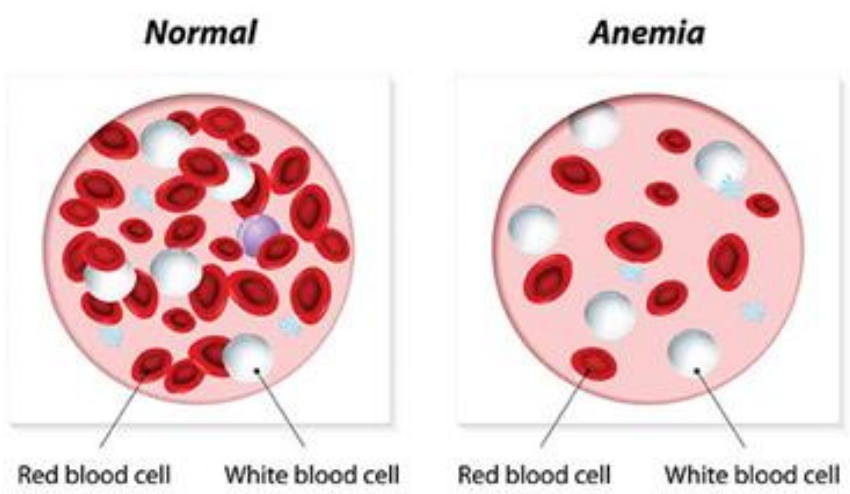

Figure 1: Normal Anaemia

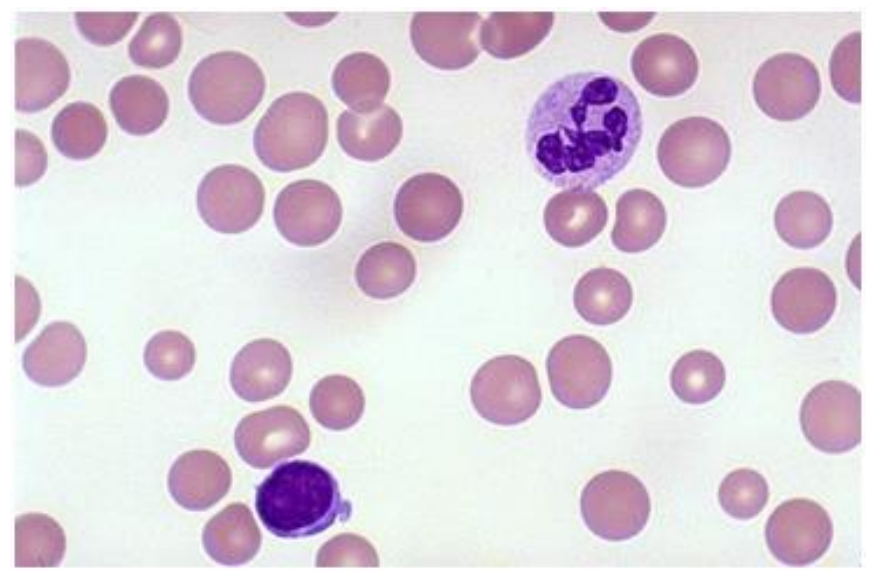

Figure 2: Megaloblastic Anaemia

\section{Discussion}

Vitamin $\mathrm{B}_{12}$ deficiency causes a moderate to severe Anaemia of slow on set. In advanced cases the Anaemia may be severe and accompanied by leukopenia and the thrombocytopenia with very low $\mathrm{HB} \%$ level s, the picture of pancytopenia will be there. In neurological symptoms peripheral nerves are usually affected first than posterior columns affected which is called as subacute combined degeneration of cord. ${ }^{[7]}$ The common age between 20 years 30years, khodke et al and Gayathri rao also reported the same age range of patients. ${ }^{[8]}$

The incidence of megaloblastic Anaemia was observed $63 \%$ in the study conducted by khunger et al shows $72 \%$. The study conducted by Ranga Swamy Et al, shows 49\%. These studies sows that megaloblastic Anaemia shows 
as one of the major causes for pancytopenia in rural part of India the estimation of folic acid and vitamin $\mathrm{B}_{12}$ levels are not available commonly so exact cause of pancytopenia is not identified routinely.

The percentage of HB levels are varied from 2.8 to $10.2 \%$ leucocyte count was in the range of 1200 to 3700 cell/cumm and platelet count from 2200 to $86000 /$ cumm. The studies conducted by the Jha et al shows almost similar results. ${ }^{[9]}$ There are number of causes of pancytopenia direct haemopoitic stem cell injury may be caused by radiation, chemotherapy, toxins, drugs and infections like tuberculosis, HIV, hepatitis C. Anaemia may be severs and always associated with reliculocytopenia. The bone marrow aspirate and bone marrow biopsy appears hypo cellular pancytopenia with norm cellular bone marrow may be due to systemic lupus erythematosus, hyper splenism. ${ }^{[10]}$ Peripheral smear shows macro ovulocytosis and anisopikilocytosis with hyper segmented neutrophils. Prabhu et al also found macro ovalocytosis with anisopikilocytosis in all cases.

Fever is also presented in few cases, the common cause begin infection to which the individuals is much more susceptible in this disease due to impaired intracellular killing of ingested bacteria by neutrophils and macrophages. ${ }^{[11]}$ Megaloblastic anemia is an important cause of cytopenias (Pancytopenia and bicytopenia) to the best of our knowledge there are not many studies quoting etc incidents and earlier series reported an incidence of pancytopenia in $43.8 \%$ and bicytopenia in $80.5 \%$ cases. $^{[12]}$

\section{Conclusion}

Megaloblastic Anaemia and pancytopenia are common heamalogolical problem in India the cases with bleeding tendencies prolonged fevers should suspect pancytopenia. The early diagnosis by history, clinical features, and peripheral smear examination plus bone marrow aspiration and vitamin $\mathrm{B}_{12}$ estimation provides the diagnosis. Early treatment can prevent neurological complications and improve prognosis of patients in pancytopenia by preventing infections.

\section{References}

1. Tariq. M. Khan N Barrier, Amin's etiology of pancytopenia prof. med. J 2010; 17; 252-6).

2. Slabler SP clinical practice with $\mathrm{B}_{\mathrm{i} 2}$ deficiency. N. Engl. J. med 2013 Jan 10 - 368(2) 149-60(PMIO:23301732.

3. Harrison's prinicples of internal medicine $19^{\text {th }}$ Edi .128 chap. Pp638 $-643$.

4. Oberley $\mathrm{MJ}$ et al. labarotory testing for cobalamine defincency in megaloblastic Anaemia AMJ. Harmator 2013 June 88(6). 522- 6

5. Farrell CI et al. Red cell or serum folate: who to do in clinic practice. Clin lab med. 2013 march 1:51(3):553-64) PM20 - 23449321.

6. Mohles DN. Leavells BS, Aplastic Anaemia: an analysis of 50 ccases Ann. Int med, 1958, 49:326 - 62.

7. Khandure U, Sharma A, Megaloblastic Anaemia : prevalence and causative factors Nalimed .J. India 2007; $20: 172-5$.

8. Tariq M Khan N Basari E, Amns Etiology of pancytopenia. Prof Med J. 2010:17:252 - 6 .

9. Jhaetal kumar Ar, clinic hematological analysis of pancytopenia: study in tertiary care center. Basic Appl. Pathol. 2012; 5: 19-21.

10. Subramanayam Y, Padma M, pancytopenia a 3 yrs. evaluation Int .J sci Res. 2015;4:1.

11. Chanarin I. The Megaloblastic anemies oxford, Blackwell scientific publications 1969;PP 344-347.

12. Sarode R, Gasewal G, madhavan N, Varma S, Ghosh, et.al.pancytopenia in nutritional megaloblastic anemia, A study from North. West India Trop Georger Med. 1989; 41:331-336.

Copyright: (C) the author(s), 2019. It is an open-access article distributed under the terms of the Creative Commons Attribution License (CC BY 4.0), which permits authors to retain ownership of the copyright for their content, and allow anyone to download, reuse, reprint, modify, distribute and/or copy the content as long as the original authors and source are cited.

How to cite this article: Reddy PS, Srinivas S. A Study on Megaloblastic Anaemia and Pancytopenia. Acad. J Med. 2019;2(2):122-24.

DOI: dx.doi.org/10.21276/ajm.2019.2.2.30

Source of Support: Nil, Conflict of Interest: None declared. 